\title{
Multidisciplinary approach in the teaching of optical technologies for electronic engineers
}

Hypolito Kalinowski, Jose Fabris, Julio de Azevedo

Hypolito Jose Kalinowski, Jose Luis Fabris, Julio Cesar Rodrigues de Azevedo, "Multidisciplinary approach in the teaching of optical technologies for electronic engineers," Proc. SPIE 3190, Fifth International Topical Meeting on Education and Training in Optics, (8 December 1997); doi:

$10.1117 / 12.294381$

Event: Fifth International Topical Meeting on Education and Training in Optics, 1997, Delft, Netherlands 


\title{
Multidisciplinary approach in the teaching of optical technologies for electronic engineers
}

\author{
Hypolito José Kalinowski, José Luis Fabris and Júlio César Rodrigues de Azevedo \\ Centro Federal de Educação Tecnológica do Paraná - CEFET/PR \\ Av. Sete de Setembro, 3165 --- 80230-901 Curitiba, Brazil \\ e-mail: hjkalin@cpgei.cefetpr.br
}

\begin{abstract}
A proposal for a multidisciplinary teaching approach, applied to optical technologies in some major fields related to electronic engineering degree is presented. The methodology involves broad overview of selected application oriented topics in several courses and laboratories.
\end{abstract}

Keywords: Teaching, Optical Technologies, Electronic Engineering, Education in Optics, Optics in Engineering, Educational Methodology

\section{INTRODUCTION}

Very fast changes are under way in all technological fields and they impose strong bias to the engineering curricula. The time necessary to a new product to reach the market is becoming very short and engineers need new and improved skills to cope with this situation during their professional careers. In the past years several activities leaded to changes in the engineering curricura in several universities along the world, co-sponsored by professional associations, national and regional boards.

The need of changes in the engineering curricula in Brazilian universities was recognized by several boards and, to speed up the process, a joint project was launched, shared by the Brazilian Research Council (CNPq), the Brazilian Foundation for Enhancement of High Education Personal (CAPES) and a branch of the Ministry of Science and Technology, the Projects \& Studies Founding Agency (FINEP). Such project, nicknamed "REENGE" (Re-engineering of the Engineering Curricula) provides a forum for discussion of educational experiences related to engineering teaching, organizes national workshops and conferences in this subject, but it also provides financial support for groups involved in new educational experiences. The support comprises new and updates equipment, funds for travel and training, comsumables, book printing, student's scholarships ...

Our group decided to experiment with a new (in our institute) way to proceed with optics eduction for electronics engineers. 


\section{OPTICS IN THE ENGINEERING CURRICULA}

Optics in Brazil has been, in past history, always considered as a "Physics" subject, with very little attention during engineering courses. However, today's engineering uses optics as an important tool for several processes and applications. Examples are optoelectronics devices for communications, remote control units and IR network links, lasers in levelling devices for building and agriculture, optical spectroscopy for materials science or maintenance, interferometry and speckle as measurements tools and standards, ... Following other activities[1,2] to attract attention of undergraduate students enrolled in electronic engineering to modern aspects of optical communications, both local and national, our group decided to introduce a new approach in the teaching of optical technologies for those students. Lecturers from four departments (Electronics, Physics, Chemistry and Mathematics) are involved in a joint project to present optics and optical technologies, as used in today's engineering activities, in an integrated, multidisciplinary overview. Subjects cover several related experimental and theoretical activities like, e.g., observation of spectral linewidth effects in diffraction and interference, that can be associated to antennae far field profile or pulse broadening in optical fibres. Mathematical, numerical and software tools are planned to model real applications of optical technologies. Activities are conducted during regular classes, as "open-labs" projects or individual student's training. Special training courses are offered for lecturers of the Institute, open also to secondary school teachers in the city.

\section{PROPOSAL}

The project involves integration of subjects in four departments: Physics (General Physics), Chemistry (Analytical Chemistry), Mathematics (Advanced Calculus) and Electronics (Electromagnetic Propagation, Optical Communications). During the initial (experimental) phase only one class of students take part in the program. A few other students are chosen to act as tutors during laboratory sessions or exercise work. The basic aim is to provide the student not isolated views of optics contents in each discipline, but an interrelated overview with emphasis in similarities or differences in the treatment of the focused problem inside each discipline. For instance, students are asked to compare linewidth effects affecting diffraction or interference patterns in general physics labs and to relate observations with corresponding near and far field effects in antennae. Linewidth effects are also emphasised during absorption measurements, starting from narrow spectral sources (Ion lasers in the Physics Department) to broader ones (semiconductor lasers and LED for optical fibre absorption) and finally to very broad sources as halogen lamps in optical spectrometers used for analytical chemistry. In parallel students shall work mathematical description of such processes, involving Fourier transforms, convolution of spectra, homogeneous and inhomogeneous broadening, etc.... 


\section{LABORATORY ENHANCEMENT}

Funds from the sponsoring programme allowed some updating of the laboratories envolved in this projetc. Initially personal computers with acquisition boards were connected to the internal network, in order to allow the exchange and sharing of data obtained in several laboratories and experimental set-ups. A few new equipment were added to each laboratoty, to improve their capacity. The equipment budget was not high and emphasis has been given to specific topis.

The Analytical Chemistry laboratory received a fiber optic dual channel spectrophotometer, whose performance stands against the old open air path spectrophotometer. Students may compare the optics complexity, resolution, optical source power and computer control of both spectrophotometers, in order to compare the technology involved in both designs. This is of valuable help to develop their skills in instruments project design.

The Physics Department received some accessories to their $\mathrm{Ar}^{+}$Ion Laser, in order to implement new laser fluorescence measurements in the undergraduate optics laboratory. They are also receiving some semiconductor visible laser diodes to be used together with the old Helium Neonium lasers. This allows several experiments comparing linewidth and coherence effects in classical optics (diffraction, interference, convolution ...). Holography experiments may also be conducted, a topic that usually catches very well the attraction of the undergraduate students.

Electronics laboratories received some optical transmission equipment, allowing several experiments using laser beams as optical carriers of information (open space transmission) or optical fiber communications experiments. The equipment also permits several measurements of fiber characteristics, that are linked to optical properties of materials both in Physics and Chemistry (attenuation due to chemical impurities or OHgroups, Rayleigh scattering, numerical aperture, near and far field diffraction patterns, ...)

\section{RELATED ACTIVITIES}

To enhance and improve optics teaching as described in previous sections, some related activities are also under development.

A textbook on Optical Fibre Propagation[3] has been translated and is in course of commercial publishing to be distributed also to other universities in Brazil. Such book encloses tutorial software for individual use with a Personal Computer, that originally was developed in DOS environment. Students and lecturers envolved in the present project developed a new version in the WINDOWS environment[4], with increased facilities for examination of light propagation inside optical fibres. Due to the "cut and paste" facilities of WINDOWS applications, it is possible to the student to move their exercises or simulation to other application as, e.g., laboratory reports. 
The expertise obtained in the previous development leaded the group to design a tutorial on optical fibre light propagation and optical systems communications, to be used by the student himself, connected via the Internet. The new tutorial, under specification and programming, utilises animated graphics to present relevant characteristics of light propagation inside optical fibres or communication systems measurements. It also includes some pieces of (almost) real time video, displaying the use of optical fibres in communications systems, optical fibre measurements and special characteristics like second harmonic generation in optical fibres. The full $\beta$ - version of the tutorial is expected to be released by the first quarter of 1998 .

Students have been incorporated in the laboratory permanent staff by means of "Scientific Initiation" scholarships. They should spend a working period around 24 hours/week in the labs and during such time they develop a research project (usually some side work of one of the main research projects in the laboratory), but they must also spend part of the time acting as tutors for laboratory or exercise activities of the class. They shall also work in the development of educational projects, updating experimental set-ups or preparing new experiments to be incorporated in a subsequent version of the project.

\section{ACKNOWLEDGEMENTS}

Authors gratefully acknowledge financial support received from the Brazilian Agencies sponsoring the "Re-engineering of the Engineering Curricula (REENGE) Programme": FINEP, CAPES and CNPq.

\section{REFERENCES}

[1] - P. Viscaya Guarin, J. C. Luna, J. C. Alvarez, A. M. Guzmán and H. J. Kalinowski; Educational Fiber Optic Transmission Equipment with Dedicated B.E.R. Features. 1991 Int. Conf. Education in Optics, St. Pettersburg(Russia). Proc. Soc. Photo Opt. Instrum. Eng. 1603 : 490-495 (1992).

[2] - H.J. Kalinowski and SBMO; A National Program to Develop the Teaching of Optical Communications in Brazil. Int. Conf. Education and Training in Optics, Pécs (Hungary). Proceedings of the Conference vol I : 76-80 (1993).

[3] - A. Ghatak, A. Sharma and R. Tewari; Undestanding Fiber Optics in a PC. Viva Books (Delhi), (1994).

[4] - E.F. Manffra and H.J. Kalinowski; Tutorial Software in the WINDOWS environment for Optical Fibre Propagation (in portuguese). Tecnologia e Humanismo, 15: 56-64 (1996). 